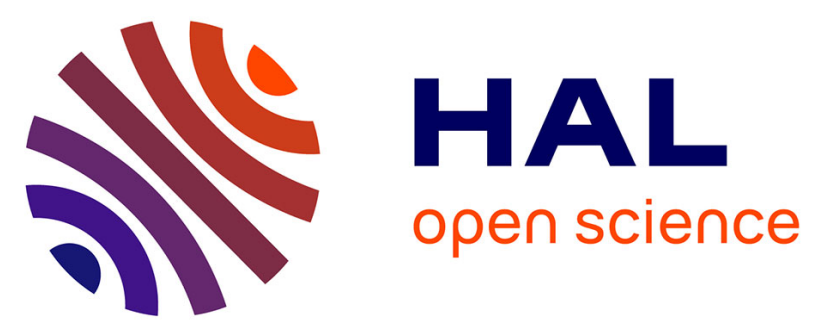

\title{
Microstructural, electrical and magnetic properties of Fe35Co65 thin films grown by thermal evaporation from mechanically alloyed powders
}

N. Redjdal, H. Salah, Thomas Hauet, H. Menari, S. M. Cherif, N. Gabouze, M. Azzaz

\section{To cite this version:}

N. Redjdal, H. Salah, Thomas Hauet, H. Menari, S. M. Cherif, et al.. Microstructural, electrical and magnetic properties of Fe35Co65 thin films grown by thermal evaporation from mechanically alloyed powders. Thin Solid Films, 2014, 552, pp.164-169. 10.1016/j.tsf.2013.12.045 . hal-01282866

\section{HAL Id: hal-01282866 https://hal.science/hal-01282866}

Submitted on 16 Aug 2016

HAL is a multi-disciplinary open access archive for the deposit and dissemination of scientific research documents, whether they are published or not. The documents may come from teaching and research institutions in France or abroad, or from public or private research centers.
L'archive ouverte pluridisciplinaire HAL, est destinée au dépôt et à la diffusion de documents scientifiques de niveau recherche, publiés ou non, émanant des établissements d'enseignement et de recherche français ou étrangers, des laboratoires publics ou privés. 


\title{
Microstructural, electrical and magnetic properties of $\mathrm{Fe}_{35} \mathrm{Co}_{65}$ thin films grown by thermal evaporation from mechanical alloying powder
}

\author{
N. Redjdal ${ }^{1,4^{*}}$, H. Salah ${ }^{2}$, T. Hauet ${ }^{3}$, H. Menari ${ }^{4}$, S.M. Chérif ${ }^{5}$, N. Gabouze ${ }^{4}$, M. \\ Azzaz ${ }^{1}$.
}

1. Laboratoire de Science et Génie des Matériaux, U.S.T.H.B., BP 32 El-Alia, Babezzouar 16311,Alger, Algeria

2. Centre de Recherche Nucléaire d'Alger, 2 Bd Frantz Fanon, Alger, Algeria

3. Institut Jean Lamour. Université de Lorraine - CNRS UMR 7198. Boulevard des Aiguillettes, BP 239. 54506 Vandoeuvre Les Nancy. France

4. Centre de Recherche en Technologie des Semi-conducteurs pour l'Energétique, $02 \mathrm{Bd}$. Frantz Fanon, Alger, Algeria

5. Laboratoire des Sciences des Procédés et des Matériaux, Institut Galilée, Université Paris13, 99, avenue J.B. Clément, 93430 Villetaneuse. France

We present a detailed study of the microstructural, electrical and magnetic properties of $\mathrm{Fe}_{35} \mathrm{Co}_{65}$ thin films deposited by thermal evaporation using nanocrystalline mixture. The nanocrystalline $\mathrm{Fe}_{35} \mathrm{Co}_{65}$ powder was prepared by mechanical alloying process using high energy ball milling and then carefully studied. Good homogeneity, purity and stoichiometry were demonstrated in the powder composed of $25 \mathrm{~nm}$ mean crystallite size. Microstuctural analysis of $\mathrm{Fe}_{35} \mathrm{Co}_{65}$ thin films ranging from 9 to $50 \mathrm{~nm}$ deposited on $\mathrm{Si}(001)$ shows that the stoichiometry is conserved over the whole thickness range and that (110) texture forms as the film thickness increases. Our work finally demonstrates that high saturation magnetization, low coercivity and high electrical resistivity FeCo thin films can be achieved by thermal evaporation from properly set mechanical alloying powder.

\footnotetext{
${ }^{*}$ corresponding authors: nabilaredjdal@yahoo.fr
} 


\section{INTRODUCTION}

There have been many studies on FeCo thin films because of their ferromagnetic properties required in applications such as magnetic sensors, MEMS devices, recording head sensors, hard magnets and high-frequency applications, where high saturation magnetization, low coercivity, high electrical resistivity or appropriate anisotropy are required. It is well known that equiatomic composition offers good magnetic properties $\left(\right.$ low $\mathrm{H}_{\mathrm{c}}$, high $\mathrm{M}_{\mathrm{s}}$ ) among FeCo alloys. More generally, $\mathrm{M}_{\mathrm{s}}$ and $\mathrm{H}_{\mathrm{c}}$ can be tuned in the range $40-70 \%$ Co content as a function of the field of use $[1,2]$. Moreover, depending on the methods used for the preparation, different physical properties are obtained. Several experimental methods have been used to optimize the experimental parameters, trying to control their influence on the magnetic and electrical properties of the grown films $[3,4,5]$. The methods used require either a reliable control of the composition and structure in designing the magnetic functionality of these materials or, such as the case of underlayer insertion, necessitate further processing and then, require more time and cost. Sputtering and molecular beam epitaxy require high or ultrahigh vacuum [6]. Apart from having separate targets that can affect reproducibility [7], the high magnetization of FeCo targets strongly interferes with the magnetic field generated by magnetron sputtering systems and reduces severely the efficiency of the magnetron system and affect the homogeneity of the films $[8,9,10]$. Electrodeposition is a low cost method but requires continuous control and regulation, especially for alloys where much more complex process is needed $[11,12]$. Besides, the growth mechanism depends on electrodeposition conditions such as electrolyte composition, electrolyte $\mathrm{pH}$ and deposition potential. The electrolyte $\mathrm{pH}$ and both $\mathrm{Co}^{2+}$ and $\mathrm{Fe}^{2+}$ concentrations were observed to change significantly the microstructure, morphology and magnetic properties of the $\mathrm{Fe}-\mathrm{Co}$ electrodeposited films [1]. 
In the present contribution, we show that combined mechanical alloying process using high energy ball milling and thermal evaporation from the nanostructured mixture powder give rise to high quality deposits. One advantage to use mechanical alloying is that the powder can be produced in large quantities and the processing parameters can be easily controlled. Then the evaporation process can be fast and reproducible. Microstuctural analysis of $\mathrm{Fe}_{35} \mathrm{Co}_{65}$ thin films ranging from 9 to $50 \mathrm{~nm}$ deposited on $\mathrm{Si}(001)$ shows that the stoichiometry is conserved over the whole thickness range. High saturation magnetization, low coercivity and high electrical resistivity FeCo thin films were obtained.

\section{EXPERIMENTAL DETAILS}

Elemental Fe and Co powders of $99.98 \%$ purity and approximated particle sizes of respectively $60 \mu \mathrm{m}$ and $40 \mu \mathrm{m}$ were used. The composition of the obtained mixture is $\mathrm{Fe}_{35} \mathrm{Co}_{65}$. The nanostructured powder preparation was assured by mechanical alloying. A planetary RETSCH PM 400 ball mill, equipped with hardened steel vials and balls, was employed for milling with a rotating speed of $290 \mathrm{rpm}$ and a ball-to-powder weight ratio (BRP) of 20 . The milling duration was chosen in such a way to obtain a nanostructured mixture and to form solid solution of FeCo, which corresponds to 12 hours. As compared to the findings of references $[13,14]$ where mechanical alloying process of FeCo alloy was investigated, the FeCo solid solution was achieved at larger times. Shokrollahi [13] found that for approximately $20 \mathrm{~h}$ of milling, the Co lines disappear, indicating the formation of the bcc $\mathrm{Fe}(\mathrm{Co})$ solid solution. 30 hours of milling were necessary in reference [14]. The mechanical alloying process of FeCo was deeply examined $(25 \mathrm{mn}-70 \mathrm{~h}$, and for 200 and $300 \mathrm{rpm}$ speed) by Li et al. [15]. They have showed that a maximum of the saturation magnetization 
was obtained for 10-h milling at $300 \mathrm{rpm}$. Under these conditions, the powder size distribution was also narrowed. But, further milling time increased the coercivity.

To minimize oxidation during the milling process, the experiments were performed under protective atmosphere of argon [16]. The microstructure characterization of the milled

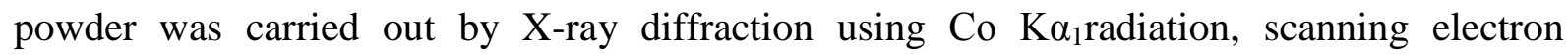
microscopy coupled to energy dispersive spectroscopy and X-ray cartography.

Characterized powder mixture was used to deposit $\mathrm{Fe}_{35} \mathrm{Co}_{65}$ films of desired thicknesses on (100) silicon substrate. The deposition was carried out by thermal evaporation under $8 \times 10^{-7}$ mbar vacuum from an electrically heated tungsten boat filled with Nanocrystalline $\mathrm{Fe}_{35} \mathrm{Co}_{65}$ powder. The deposition rate was $2.8-5 A^{\circ} \mathrm{s}^{-1}$. The films were deposited at room temperature without heating the substrates.

The film thickness and composition were determined using Rutherford backscattering spectrometry. Crystallographic properties, topography and granularity of the evaporated layers were performed by X-ray diffraction and atomic force microscopy. The surface morphology of the deposits was investigated using a Nanoscope Dimension 3100 atomic force microscope. The resistivity of the samples was measured by usual current in-plane four probe methods. The static magnetic properties of the $\mathrm{Fe}_{35} \mathrm{Co}_{65}$ films were studied using a commercial vibrating sample magnetometer (VSM) technique.

\section{RESULTS AND DISCUSSION}

\subsection{Powder Characterization}

$\mathrm{XRD}$ analysis of the FeCo mixture powder, in the $2 \theta$ scan range $40^{\circ}-150^{\circ}$, revealed the presence of cubic structure with (110) preferentially oriented plane as shown in Fig.1. The XRD pattern display Bragg reflection peaks at $2 \theta=52.97,78.1,100.9,125.88$ corresponding 
respectively to (110), (200), (211), (220) planes. No contamination or oxide formation was detected. 12 hours of high milling energy lead to the disappearance of the Fe and Co peaks and the formation of FeCo solid solution, suggesting that the FeCo bcc structure is formed.

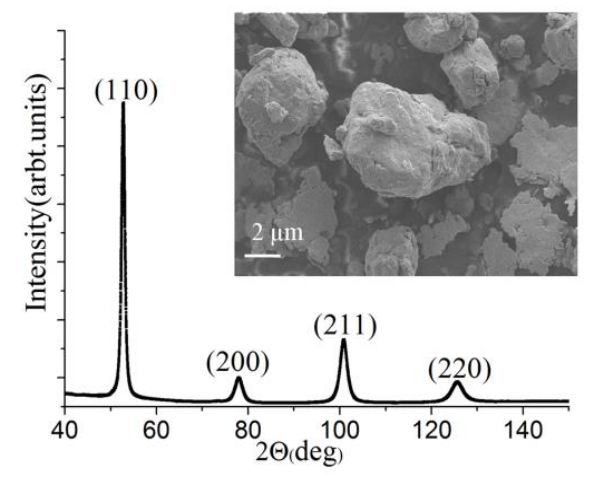

Fig.1. XRD patterns of $\mathrm{Fe}_{35} \mathrm{Co}_{65}$ powder mixture. In insert, SEM micrographs obtained for $\mathrm{Fe}_{35} \mathrm{Co}_{65}$ powder mixture milled during 12 hours.

The size of the crystallite particles in the powder was determined using Rietveld fitting from the XRD pattern. The main value is found to be equal to $25 \mathrm{~nm}$.

During high-energy milling the powder particles are repeatedly flattened, cold welded, fractured and re-welded. This process increases the chances to get a homogeneous mixture. Insert in Fig. 1 shows one typical SEM micrographs of the obtained mixture. With time, the initial spherical particles disappear and Fe-Co powder aggregates into nanostructured particles. The composite particles at this stage have a characteristic layered structure consisting of various combinations of the starting constituents.

The X-ray cartography of Fe and Co elements is given in Fig.2. The comparison between the colors fields reveals cobalt particles dispersed within the iron particles and shows a homogeneous distribution of Fe and Co. Besides, EDS analysis (not shwon here) showed that 12 hours of high energy ball milling provides alloys with initial stoichiometry $35 \% \mathrm{Fe}$ and 
$65 \%$ Co. No contamination was found even from the material constituents of balls and vials $(\mathrm{Cr})$

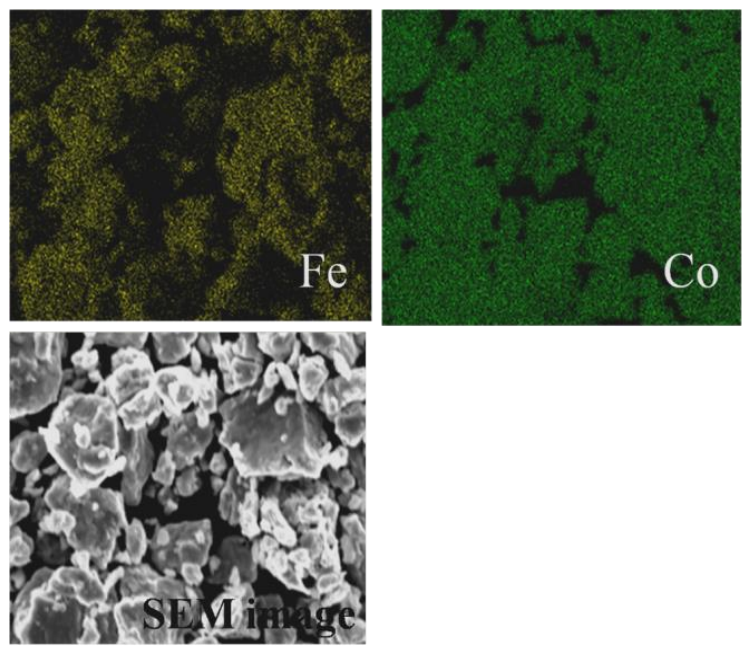

Fig.2. X-ray cartography giving the distribution of iron and cobalt elements on a nanostructured mixture $\mathrm{Fe}_{35} \mathrm{Co}_{65}$ aftermilled for 12 hours.

\subsection{Film Characterization}

\section{A. Microanalysis}

The elemental composition and the thickness of the deposited films were obtained using RBS microanalysis. The measurements were carried out using $2 \mathrm{MeV}$ alpha beam, issued from a 3.75 MV Van de Graff accelerator. The intensity of the beam was chosen sufficiently low to prevent undesirable effects such as atom or molecule desorption and sample heating. All the samples were analyzed under the same current charge of $5 \mu \mathrm{C}$. The backscattered particles were detected at $165^{\circ}$ using an implanted semiconductor junction of $11 \mathrm{keV}$ energy resolution. These conditions allowed us to separate the energy peaks corresponding to Fe (55.84 uma) and Co (58.93 uma), as shown in Fig.3 and to accurately determine the composition and thickness of the analyzed films. RBS data processing led to 
thickness value varying in the range $9-50 \mathrm{~nm}$ and film composition varying from $65 \%$ to $67 \%$ for Co and $35 \%$ to $33 \%$ for Fe. RBS analysis confirmed that there was no contamination of the evaporated films. For clarity, the energy spectra shown in the figure are limited to three different thicknesses $(9,20$ and $50 \mathrm{~nm})$. The insert of Fig.3 represents a zoom of the peaks corresponding to backscattered alpha particles from $\mathrm{Fe}$ and $\mathrm{Co}$ atoms.

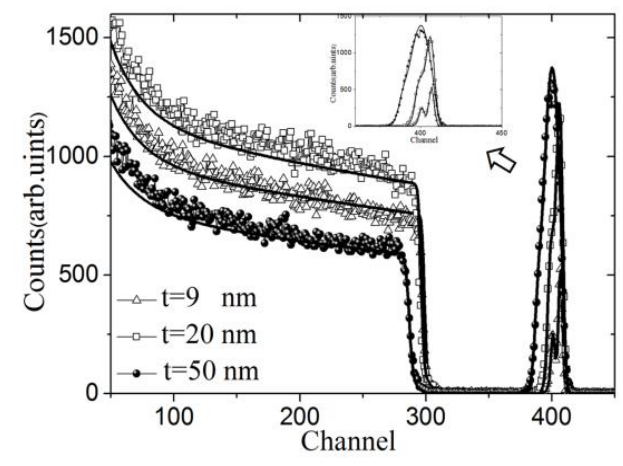

Fig. 3. RBS energy spectra collected at $165^{\circ}$ for $\mathrm{Fe}_{35} \mathrm{Co}_{65}$ films deposited on silicon substrate, using $2 \mathrm{MeV}$ alpha particles. Solid lines correspond to fitted spectra. Insert of fig. 3 represents a zoom of the peaks corresponding to backscattered alpha particles from Fe and Co atoms

\section{B. Crystalline structure}

The crystalline structure of the deposited films was studied using XRD technique. The reflectometry patterns shown in Fig.4 are reported for thicknesses 9, 20 and $50 \mathrm{~nm}$. A crystalline texture with preferentially oriented (110) plane is observed for thicknesses higher than $20 \mathrm{~nm}$. The (110) peak intensity grows with increasing film thickness. The same behavior is observed for the (211) peak. Its intensity is, however, much lower than that of the (110) peak. 


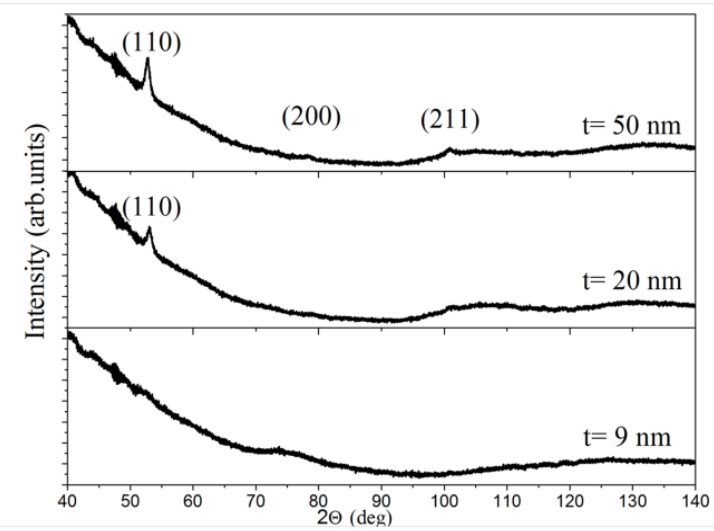

Fig.4. XRD patterns of $\mathrm{Fe}_{35} \mathrm{Co}_{65}$ films evaporated on $\mathrm{Si}(100)$ having 9, 20, and $50 \mathrm{~nm}$ thickness

C. Topography

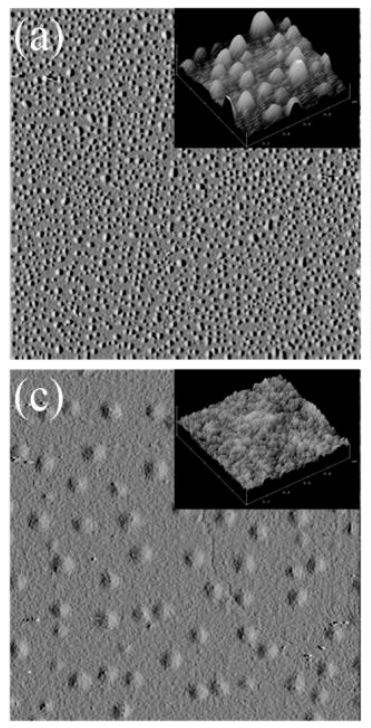

Fig.5. Surface morphology of $\mathrm{Fe}_{35} \mathrm{Co}_{65}$ films evaporated on $\mathrm{Si}$ (100) for different thicknesses (a) $\mathrm{t}=9 \mathrm{~nm}$, (b) $\mathrm{t}=\mathbf{2 0} \mathrm{nm}$, (c) $\mathrm{t}=50 \mathrm{~nm}$, obtained by AFM scan over $10 \mu \mathrm{m} * 10 \mu \mathrm{m}$ surface. The insert of fig. 5 show a $3 \mathrm{D}$ plot of a $1 \mu \mathrm{m} * 1 \mu \mathrm{m}$ zoom. 
Fig.5 compares AFM images obtained for 9, 20 and $50 \mathrm{~nm}$ thick $\mathrm{Fe}_{35} \mathrm{Co}_{65}$ films, corresponding to figures $\mathrm{a}, \mathrm{b}$ and $\mathrm{c}$ respectively.

A homogenous distribution of the $\mathrm{Fe}_{35} \mathrm{Co}_{65}$ crystalline grains is observed for the three thicknesses.

As summarized in Table 1, the particle size increases, from about $100 \mathrm{~nm}$ to $200 \mathrm{~nm}$ as the films grow from 9 to $50 \mathrm{~nm}$. The surface roughness shows a minimum at $20 \mathrm{~nm}$. This tendency is also observed by Lin et al. [7] for $\mathrm{Co}_{40} \mathrm{Fe}_{60}$ obtained by RF magnetron sputtering.

This result can be explained by a growing process that starts by grain nucleation and ends with grains coalescence.

Table 1. Surface morphology data of $\mathrm{Fe}_{35} \mathrm{Co}_{65}$ films evaporated on $\mathrm{Si}$ (100) determined from AFM scan size $10 \mu \mathrm{m} * 10 \mu \mathrm{m}$.

\begin{tabular}{ccc}
\hline $\begin{array}{c}\text { Thickness } \\
(\mathbf{n m})\end{array}$ & $\begin{array}{c}\text { RMS } \\
\text { roughness } \\
(\mathbf{n m})\end{array}$ & $\begin{array}{c}\text { Average } \\
\text { diameter particle } \\
\text { size (nm) }\end{array}$ \\
\hline $\mathbf{9}$ & 5.35 & 95 \\
$\mathbf{2 0}$ & 2.10 & 159 \\
$\mathbf{5 0}$ & 2.49 & 198 \\
\hline
\end{tabular}

\section{Electrical behavior}

Electrical resistivity measurements were performed at room temperature, using current in-plane four point probe method (Digital Four Probe research model). Figure 6 illustrates the measured resistivity of $\mathrm{Fe}_{35} \mathrm{Co}_{65}$ films deposited on $\mathrm{Si}$ (100) substrate. The electrical resistivity decreases rapidly while increasing film thickness from $9 \mathrm{~nm}$ to $17 \mathrm{~nm}$ whereas only a shallow decrease is obtained for thicker films. In the whole range of 
thickness considered here, the experimental values of $\rho$ are much higher than the common crystalline FeCo bulk resistivity that is of the order of 1 to $10 \mu \Omega$.cm depending of the order parameters. Presence of impurities cannot explain such a high values since no contamination was detected by XRD and RBS analysis. However, our FeCo film has a granular structure where grain boundaries and inner structural defect play a major role in the electrical transport $[17,18]$.For comparison with the literature, a value of $118 \mu \Omega . c m$ was reported for $60 \mathrm{~nm}$-thick granular $\mathrm{Fe}_{60} \mathrm{Co}_{40}$ film [18]. It is to note that we performed the same measurement on $\mathrm{Fe}_{35} \mathrm{Co}_{65}$ deposited on glass substrate and a very similar behavior is obtained (not shown here). Let's now try to verify the role of the grains finite size on the resistivity. First, we can test the influence of the surface scattering effects on the thickness dependence of the resistivity using the Fuch-Sondheimer model $[19,20]$.

$\rho_{=} \rho_{b}\left[1+\left(l_{m} / t\right)(1-p)(3 / 8)\right]$

where $1_{\mathrm{m}}$ is the bulk FeCo electron mean free path whose value is about $20 \mathrm{~nm}$ in crystallized FeCo alloys, $\mathrm{t}$ is the film thickness and $\mathrm{p}$ is a parameter varying from 0 to 1 and accounting for the elastically scattered electrons. This model is supposed to be accurate for $t<1_{m}$. As shown on Fig. 6, at best, a variation of $10 \%$ of resistivity is calculated from $20 \mathrm{~nm}$ to $9 \mathrm{~nm}$. Therefore surface scattering effects does not account for the decrease of the resistivity as a function of thickness observed in our FeCo films.

In order to estimate the effects of the grain boundary scattering on the electrical resistivity, we considered the model of Mayadas and Shatzkes. In this model, the resistivity is evaluated with $[19,20,21]$.

$\rho_{g} / \rho_{0}=\left[1-(3 / 2) \alpha+3 \alpha^{2}-3 \alpha^{3} \ln (1+1 / \alpha)\right]^{-1}$ 
with

$\alpha=\left(l_{m} / D\right)(R / 1-R) \quad(\mathrm{R}=0 \sim 1)$

where $\rho_{\mathrm{g}}$ is the film resistivity including electron grain boundary scattering and R represents a reflection coefficient on the grain boundaries whose value has been usually chosen as 0.3 for FeCo polycrystalline films $[18,22]$. We used $1_{\mathrm{m}}=20 \mathrm{~nm}$ and $\rho_{0}=60 \mu \Omega$.cm. Figure 6 shows the fit based on Mayadas-Shatzkes model that has no other free parameter than the grain sized D. We can first note that this fit is in very good agreement with the experimental resistivity data.

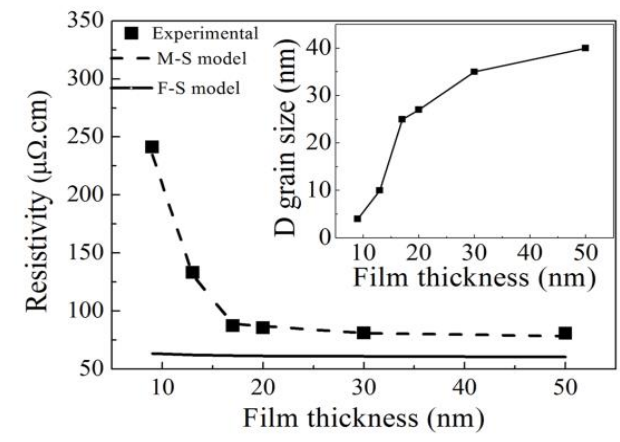

Fig.6. Electrical resistivity vs. film thickness measured for $\mathrm{Fe}_{35} \mathrm{Co}_{65}$ films evaporated on Si (100) substrate. The dots correspond to the measured data. The solid line corresponds to the Fuch-Sondheimer model. The dashed line corresponds to the Mayadas-Shatzkes model. In insert, the values of grain size used for the different thicknesses in the Mayadas-Shatzkes fit are reported.

The values of grain size that allows this good fit are reported in insert in Fig. 6. One can notice that the grain size seems to follow very closely the thickness of the film and tends to saturate for high thicknesses.

Such variation of the grain size with the film thickness has already been often reported [23, $24,25]$. Finally, it is to note that the resistivity value that we have to inject as bulk resistivity 
in both models (about $60 \mu \Omega . \mathrm{cm}$ ) is still quite high as compared with the resistivity of bulk crystalline FeCo film. This may be due to weak cristallinity inside the grains since Fig. 4 does not show any sign of texture below $20 \mathrm{~nm}$.

\section{E. Magnetic behavior}

The magnetic properties of the $\mathrm{Fe}_{35} \mathrm{Co}_{65}$ films were checked by using a vibrating sample magnetometer in recording magnetization versus applied magnetic field. We first verified that the magnetization tends to stay parallel to the film plane because of a strong demagnetizing field. When the field is applied perpendicularly to the film plane, a reversal loop is observed typical of a magnetically hard axis loop (not shown here). This behavior is similar for all the tested FeCo thicknesses.

More interesting is the FeCo magnetization behavior under in-plane field. Fig. 7presents the magnetic hysteresis loops for 9, 20 and $50 \mathrm{~nm} \mathrm{Fe}_{35} \mathrm{Co}_{65}$ film thicknesses, recorded at three different angles $0^{\circ}, 45^{\circ}$ and $90^{\circ}$ relative to the [110] direction of the $\mathrm{Si}$ substrate.

For all measured films, the magnetization at saturation (up to 7 Tesla) is about $2000 \mathrm{emu} / \mathrm{cm}^{3}$. The curves show a square-like loop shape smoothly tilted with tails. When the film thickness increases, the loop squareness improves (the magnetization at remanence increases from 0.84 at $9 \mathrm{~nm}$ to 0.9 at $50 \mathrm{~nm}$ ) and the coercive fields increases from 71 Oe at $9 \mathrm{~nm}$ to 115 Oe at 50nm. Our results are slightly better than those found in Ref. [7] where RF magnetron sputtering method leads to $\mathrm{H}_{\mathrm{c}}$ value of 143 Oe for $40 \mathrm{~nm}$ thick $\mathrm{Fe}_{35} \mathrm{Co}_{65}$ film.In [1], Qiang et al. found even higher $M_{s}$ value (close to $2500 \mathrm{emu} / \mathrm{cm}^{3}$ ) and $\mathrm{H}_{\mathrm{c}}$ around 50 Oe for $\mathrm{H}_{\mathrm{c}}$ for $65 \%$ Co but the precision on Co content (targeted to be 65\%) was poor due to the existence of an anomalous codeposition during the electrodeposition process [1]. 


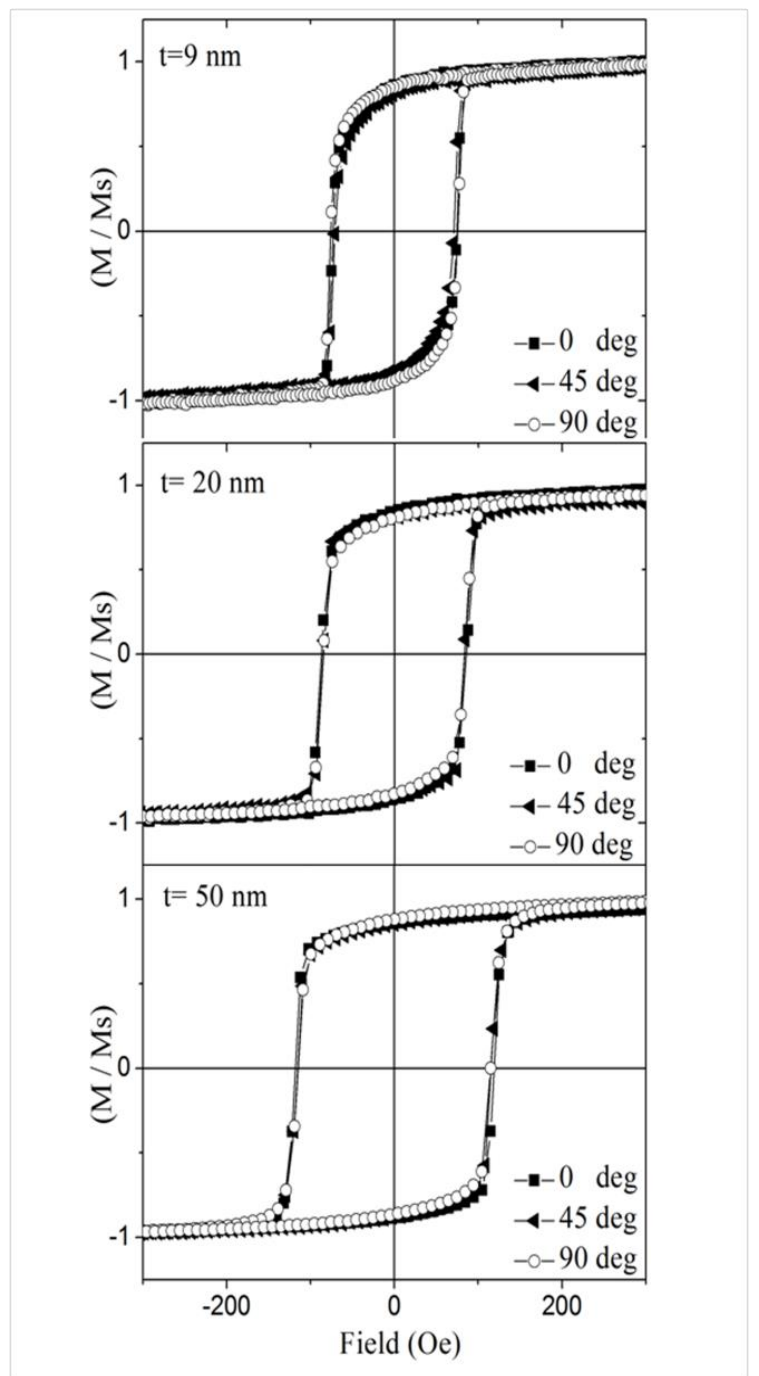

Fig.7. VSM measurement of $\mathrm{Fe}_{35} \mathrm{Co}_{65}$ respectively $9 \mathrm{~nm}, 20 \mathrm{~nm}$ and 50nm thick. For each samples, magnetization is recorded along three different direction of magnetic field $0^{\circ}$, $45^{\circ}$ and $90^{\circ}$ relative to the (110) direction of the Si substrate.

The low value of $\mathrm{H}_{\mathrm{c}}$ and high magnetization at saturation, together with high magnetization at remanence is very interesting in the view of developing sensors active layers or for highfrequency applications [26]. Enhancement of $\mathrm{H}_{c}$ with increasing thickness is usually due to the enhanced roughness, increased number of grain boundaries and island-like morphology of the grains $[27,28]$. In that case, the reversal mechanism is dominated by domain wall pinning [29].The increase of $\mathrm{H}_{c}$ with film thickness may rather be explained by film crystallinity. 
Good film smoothness and homogeneity also appears through high squareness for the magnetic hysteresis loops.

However, regarding in-plane anisotropy, the measurements performed at $45^{\circ}$ and $90^{\circ}$ relative to the (110) direction of the Si substrate don't show any significant difference with the $0^{\circ}$ results. Therefore, our results suggest that the coercivity variation with film thickness must originate from the grain structure variation.

\section{Conclusion}

To sum up, we have demonstrated a high quality $\mathrm{Fe}_{35} \mathrm{Co}_{65}$ film deposition from thermal evaporation of a well controlled nanocrystalline $\mathrm{Fe}_{35} \mathrm{Co}_{65}$ powder. This powder is prepared by mechanical alloying process using high energy ball milling. The powder and deposits were carefully characterized using several techniques. As evidenced by RBS and $\mathrm{XRD}$ analysis, the stoichiometry was conserved from the crystallite particles in the powder to the evaporated films. No oxides, silicides or other impurities were revealed, in spite of the reactivity of the $\mathrm{FeCo} / \mathrm{Si}$ interface. The electrical resistivity of the deposited films was measured. High resistivities of the order of $250 \mu \Omega$.cm have been found for low thickness and are thought to come from the granular structure of the CoFe film. Finally, moderate coercivity, high saturation magnetization and high remnant magnetization were measured. In particular, for films thinner than $10 \mathrm{~nm}$, relatively low coercivity (710e) and high saturation (about $2000 \mathrm{emu} / \mathrm{cm}^{3}$ ) magnetization were obtained simultaneously. We believed that our work offers a new method for growing FeCo thin films with good features for sensors active layers or for high-frequency applications.

We believe that our work offers a method for growing FeCo thin films that can comply with the application needs for quasi-static high magnetization materials. For high- 
frequency applications, concentration must be tuned to lower anisotropy and coercivity. Then, susceptibility and magnetostrictive characterization would be required to insure implementation feasibility.

\section{ACKNOWLEDGMENTS.}

The authors express their gratitude to Professor S. Mangin and CC Magnetisme from the Institut Jean Lamour- University of Lorraine for help with magnetic characterizations.

N. Redjdal likes to express her sincere thanks to Professor P. Franciosi from the LSPM laboratory of the University of Paris 13 for permitting her to visit the laboratory, and thanks Mr O. Brinza, Mr E. Ait, Mr T. Chauveau for their kind technical assistance. N. Redjdal is very grateful to Mr I. Redjdal for the financial help.

\section{References}

[1] C. Qiang, J. Xu, S. Xiao, Y, Jiao Z. Zhang, Y. Liu, L. Tian, Z. Zhou, Applied Surface Science. 257 (2010) 1371.

[2] C. Rizal, J. Kolthammer, R. K. Pokharel, and B. C. Choi, J. Appl. Phys. 113 (2013) 113905.

[3] J. Zarpellon, H.F. Jurca, N. Mattoso, J.J. Klein, W.H. Schreiner, J.D. Ardisson, W.A.A. Macedo, D.H. Mosca, Journal of Colloid and Interface Science. 316 (2007) 510.

[4] H.S. Jung, W.D. Doyle, S. Matsunum, J. Appl. Phys. 93 (2003) 6462.

[5] X. Liu, H. Kanda, A. Morisako, Journal of Physics: Conference Series 266, 012037 (2011). $2^{\text {nd }}$ Int.Symp.on Advanced Magnetic Materials and Applications (ISAMMA 2010).

[6] K. Dumesnil and S. Andrieu, Molecular Beam Epitaxy: From Quantum Wells to Quantum Dots. From Research to Mass Production.(Chapter 20), Ed. M. Henini, ELSEVIER (2012)

[7] C.H. Lin, W.H. Chen, J.S. Tsay, I.T. Hong, C.H. Chiu , H.S. Huang, Thin Solid Films. $519(2011) 8379$.

[8] C.T. Liu, M.C. Lai, and C.C. Hwang, IEEE Transactions On Magnetics. 46 (2010) 6

[9] W. Weidong, C. Zhimei, G. Dangzhong, H. Yong, Z. Yongming, T. Yongjian, Nuclear Instruments and Methods in Physics Research Section A. 480 (2002) 98. 
[10] Takayuki Iseki, Vacuum. 84 (2010) 339

[11] S. N. Srimathi, S. M. Mayanna and B. S. Sheshadri. Surface Technology. 16 (1982) 277.

[12] B. Koo, B. Yoo, Surface \& Coatings Technology. 205 (2010) 740.

[13] H. Shokrollahi, Materials and Design. 30 (2009) 3374

[14] B.H. Lee, B. S. Ahn, D.G. Kim , S.T. Oh, H. Jeon , J. Ahn , Y. Do Kim, Materials Letters. 57 (2003) 1103

[15] H.F. Li and R.V. Ramanujan, Journal of Electronic Materials. 33 (2004) No. 11.

[16] R. Elkalkouli, M. Grosbras, J.F. Dinhut, Nanostructured Materials. 5 (1995) 733.

[17] M. Vopsaroiu, M.J. Thwaites, G.V. Fernandez, S. Lepadatu, K. O’Grady. Journal of Optoelectronics and Advanced Materials, 7 (2005) 2713.

[18] J.P. Rivière, P. Bouillaud, J.F. Dinhut, J. Delafond, Thin Solid Films. 176 (1989) L161.

[19] A.F. Mayadas, M. Shatzkes, Phys. Rev. B. 1 (1970) 1382.

[20] J-W. Lim, K. Mimura, M, Isshiki, Applied Surface Science.217 (2003) 95.

[21] J.M. Camacho, A.I. Oliva, Thin Solid films.515 (2006) 1881.

[22] D. Schumacher, Thin Solid Film 152. (1987) 499.

[23] X. Zhang, X. Song, X-G. Zhang, D. Zhang, EPL, 96 (2011) 7010.

[24] A. Pal, S. Chaudhuri, Journal of materials Science, 11 (1976) 872.

[25] J-W. Lim, M. Isshiki, J. Appl. Phys. 99 (2006) 094909.

[26] Y.P. Wu, G-C. Han, L.B. Kong, Journal of Magnetism and Magnetic Materials.322 (2010) 3223.

[27] J. Swerts, K. Temst, N. Vandamme, B. Opperdoes, C. Van Haesendonck, Y. Bruynseraede, Thin Solid Films.413 (2002) 212.

[28] F. Albertini, L. Nasi, F. Casoli, S. Fabbrici, P. Luches, A. Rota, S. Valeri, Journal of Magnetism and Magnetic Materials.316 (2007) e158.

[29] F.T. Yuan, A.C.Sun, J. H. Hsu, C.S. Tan, P.C. Kuo, W. M. Liao, H.Y. Lee, J. Appl. Phys. 108 (2010) 113909. 